\title{
miRNA-182-5p promotes human bladder cancer proliferation and migration through the FOXF2/SHH axis
}

\author{
Ze ZHANG ${ }^{1,2, *}$, Chong WANG ${ }^{1,2, *}$, Tiantian LIU $^{1,2}$, Zhao TANG ${ }^{1}$, Rucheng YAN ${ }^{1}$, Chen ZHANG ${ }^{1}$, Chao CHENG ${ }^{1,2}$, Jiawei WANG ${ }^{1,2}$, Hao WANG ${ }^{1,2}$, \\ Houbao HUANG ${ }^{1, *}$, Yawei $\mathrm{LI}^{1, *}$ \\ ${ }^{1}$ Department of Urology, The First Affiliated Hospital of Wannan Medical College (Yijishan Hospital of Wannan Medical College), Wannan \\ Medical College, Wuhu, China; ${ }^{2}$ Key Laboratory of Non-coding RNA Transformation Research of Anhui Higher Education Institution, Wannan \\ Medical College, Wuhu, China
}

*Correspondence: drhuanghoubao@163.com; liywyjsyy@163.com

\#Contributed equally to this work.

Received September 3, 2021 / Accepted December 5, 2021

\begin{abstract}
Increasing evidence suggests that microRNAs (miRNAs) play critical roles in bladder tumorigenesis and development by combining with the 3' untranslated regions (3'-UTRs) of the corresponding mRNAs to negatively regulate gene expression. The role of miR-182-5p in bladder cancer (BC) remains unclear. Therefore, this study aimed to clarify the functional role of miR-182-5p in BC. We predicted candidate mRNAs for miR-182-5p via three databases (TarBase, ENCORI, and miRDB). Dual-luciferase reporter assays and target prediction confirmed FOXF2 as a potential target of miR-182-5p. Quantitative RT-PCR (qRT-PCR) showed that endogenous miR-182-5p expression was significantly upregulated in BC cell lines and clinical samples of BC patients. IHC, western blotting, and qRT-PCR assays indicated that FOXF2 expression was concurrently downregulated in BC tissues and BC cell lines. Gain- and loss-of-function studies showed that the overexpression of miR-182-5p enhanced the proliferation and migration of BC cells, while the downregulation of miR-182-5p showed the opposite results. The effects induced by miR-182-5p were attenuated with the restoration of FOXF2 expression. In BC cells, the upregulation of miR-182-5p not only decreased FOXF2 expression but also markedly increased Sonic hedgehog (SHH) pathway levels. These findings suggested that FOXF2 directly binds to miR-182-5p and that miR-182-5p acts as a tumor promoter in $\mathrm{BC}$ genesis and metastasis by targeting FOXF2. In addition, miR-182-5p plays a pro-cancer role by downregulating FOXF2 and activating the SHH pathway.
\end{abstract}

Key words: miR-182-5p, FOXF2, SHH signaling pathway, bladder cancer

The incidence of bladder cancer (BC) has been on the rise in recent years and accounts for a significant proportion of cancer-related deaths [1]. There are two common types of BC with different biological properties as follows: non-muscleinvasive BC (NMIBC) and muscle-invasive BC (MIBC) [2]. More than $70 \%$ of patients are diagnosed with NMIBC, and the recurrence rate is as high as $50-70 \%$ [3]. If diagnosed as a high-grade invasive muscle tumor, the disease can rapidly progress to metastasis and even death. Currently, surgical resection is considered to be the primary treatment option for NMIBC $[4,5]$, while multimodality therapy, such as radical cystectomy combined with neoadjuvant chemotherapy, offers the best chance of survival for MIBC $[6,7]$. The overall survival of metastatic $\mathrm{BC}$ remains low despite the availability of multiple treatment regimens [8]. Therefore, it is important to further understand the molecular mechanisms of $\mathrm{BC}$ occurrence and metastasis to identify new preventive and therapeutic strategies to improve the prognosis of patients.

miRNAs are only 18-22 nucleotides in length [9], and many studies have shown that miRNAs inhibit or promote drug resistance, apoptosis, proliferation, and other phenotypes in different types of tumors by regulating tumor suppressor genes or oncogenes [10]. For example, in bladder cancer cells, miR-626 inhibits EYA4, thereby promoting proliferation [11]. miR-558 promotes bladder cancer invasion, migration, and angiogenesis by decreasing the expression level of heparanase (HPSE) [12]. Therefore, miRNAs have attracted increasing attention as potential targets for the treatment of BC.

miR-182-5p has been reported to play an important role in a variety of cancers. For instance, miR-182-5p inhibits tumorigenesis, lymphangiogenesis, and angiogenesis in colon cancer [13], and it reverses cisplatin resistance in lung 
cancer [14]. In addition, miR-182-5p promotes cell migration, proliferation, and colony formation in breast cancer [15], and it inhibits FOXO3a to promote hepatocellular carcinoma progression [16]. However, there are few studies on the function of miR-182-5p in BC and its related mechanisms.

FOXF2 has been reported as a tumor suppressor gene in other cancer types. For example, FOXF2 gene deficiency has been demonstrated to promote epithelial-mesenchymal transformation and aggressiveness in breast [17] and lung cancer [18]. However, FOXF2 has not been reported in BC. It has been reported that miR-182-5p targets the FOXF2 gene and regulates the proliferation and invasive ability of ovarian cancer [19], but its regulatory mechanism in BC has not been elucidated. In the present study, we demonstrated that FOXF2 is a direct downstream target of miR-182-5p and that FOXF2 suppresses the proliferation and migration of BC cells. We also found that miR-182-5p enhances the malignant behavior of BC cells by promoting the Sonic hedgehog (SHH) pathway. Our study suggests that miR-182-5p has potential as a diagnostic and therapeutic target for BC.

\section{Patients and methods}

Clinical samples. A total of 36 pairs of adjacent normal tissues (at least $3 \mathrm{~cm}$ from the tumor) and $\mathrm{BC}$ tissues were collected at the First Affiliated Yijishan Hospital of Wannan Medical University from 2019 to 2021. All samples were identified by the Department of Pathology of the First Affiliated Hospital of Wannan Medical College. All samples were collected after informed consent was obtained. The present study received approval from the Ethics Committee of Wannan Medical College.

Cell culture. Bladder cancer cell lines (BIU-87, 5637, EJ, and T24) and SV-HUC-1 cells (normal human urothelial cells) were purchased from the Chinese Academy of Sciences Cell Bank (Shanghai, China). Bladder cancer cell lines were cultured in RPMI-1640 medium (HyClone, Beijing, China), and SV-HUC-1 cells were cultured in an F-12 K medium (Gibco, USA). Both media contained 10\% fetal bovine serum (FBS; Yesen, Shanghai, China). Cells were maintained at $37^{\circ} \mathrm{C}$ with $5 \% \mathrm{CO}_{2}$.

qRT-PCR. Total RNA was isolated from BC tissues with TRIzol reagent (Invitrogen), and miRNA reverse transcription was performed using a reverse transcription kit (TianGen, Beijing, China). For miRNA qRT-PCR analysis, cDNA samples were analyzed using the miRNA qPCR Detection Kit (SYBR Green) following the manufacturer's protocol (TIANGEN). The relative expression of genes was determined with the $2^{-\triangle \Delta C T}$ method. Detailed information is presented in the attached list.

Western blotting. Total tissue or cellular protein was extracted with RIPA lysis buffer. Protein lysates were subjected to 10\% SDS-PAGE (Cat\# PG112, EpiZyme Biotechnology, China), and proteins were transferred to polyvinylidene fluoride (PVDF) membranes by electrophoresis. The antibodies used in this study included anti-FOXF2 (1:2000, \#36859, SAB), anti-SHH (1:3000, DF7747, Affinity Biosciences, Changzhou, China), anti-SMO (1:1000, DF5152, Affinity), anti-GLI1 (1:3000, DF7523, Affinity), anti- $\beta$-actin (1:10000, AF7018, Affinity), and goat anti-rabbit secondary antibody (1:10000, BA1054, Boster, China). Endogenous actin was used as a reference for normalization.

EdU assay for proliferation. To detect cell proliferation, we used the EdU Cell Proliferation Assay Kit purchased from RiboBio (Guangzhou, China) according to the manufacturer's protocol. The results were observed and imaged using an inverted fluorescence microscope (Nikon Corp., Tokyo, Japan) with 460-550 nm excitation wavelengths. The results were quantitatively analyzed using ImageJ software.

Colony formation assay. A total of $5 \times 10^{2} \mathrm{~T} 24 / 5637$ cells (48 h after transfection) were plated in 6-well plates. After 12 days when the cells formed obvious colonies, the colonies were washed with phosphate-buffered saline (PBS), fixed with $4 \%$ paraformaldehyde for $15 \mathrm{~min}$, and stained with $0.1 \%$ crystal violet for $15 \mathrm{~min}$.

Wound-healing assay. After transfection for $48 \mathrm{~h}, 1 \times 10^{5}$ T24/5637 cells were plated into 6-well plates and cultured for 24 to $48 \mathrm{~h}$, until they formed a monolayer. A $200 \mu \mathrm{l}$ pipette tip was used to scratch the cell monolayer and cells were washed twice with PBS to remove detached cells. A fresh medium with $2 \%$ serum was added and cells were cultured for $24 \mathrm{~h}$ to allow wound closure.

Transwell cell migration assay. A Transwell migration chamber was used for migration experiments. Cells $\left(1 \times 10^{4}\right)$ were seeded into the upper chamber and $500 \mu \mathrm{l}$ of medium containing $10 \%$ FBS was added to the lower chamber. Cells were cultured for $24 \mathrm{~h}$, fixed with methanol, and stained with $0.1 \%$ crystal violet.

IHC staining. For immunohistochemical staining, paraffin-embedded sections were used. Paraffin sections of BC were incubated with an anti-FOXF2 antibody (1:200, \#36859, SAB), and the percentage of FOXF2-positive cell area was quantified using ImageJ.

Luciferase reporter assay. T24 cells were seeded into 24-well plates. When cells reached $70-80 \%$ confluence, miR-182-5p mimics or negative control (NC), as well as wild-type FOXF2 (FOXF2-WT) or mutant FOXF2 (FOXF2MUT) plasmids, were co-transfected using the Lipofectamine 8000 transfection reagent (Beyotime, Shanghai, China). The dual-luciferase plasmid was purchased from Shanghai GenePharma (Shanghai, China). A dual-luciferase reporter gene assay kit (GenePharma) was used for luciferase reporter detection $48 \mathrm{~h}$ after transfection.

Tumor xenografts in nude mice. All animal experiments were approved by the Animal Care Committee of Wannan Medical College. All experimental procedures followed ARRIVE (http://www.nc3rs.org.uk/arrive). Fourweek-old female BALB/c athymic nude mice were obtained from the Model Animal Research Center of Nanjing University (Nanjing, Jiangsu, China). T24 cells transfected 
with negative control or miR-182-5p mimics were harvested and resuspended in PBS. Cells $\left(1 \times 10^{7}\right.$ cells $)$ were injected subcutaneously into the right axilla of each nude mouse. Tumor length (L) and width (I) were measured weekly with calipers to calculate the tumor volume.

Statistical analysis. Data are expressed as the mean \pm SD. Differences between groups were estimated using the $\chi^{2}$-test or Student's t-test. A p-value $<0.05$ was considered statistically significant. All results were analyzed using Prism 8.0 and SPSS 25.0.

\section{Results}

miR-182-5p is highly expressed in BC cell lines and tissues. We detected the expression level of miR-182-5p in BC cells and 36 pairs of BC tissues using qRT-PCR, and we demonstrated that miR-182-5p was highly expressed in BC tissues and cells (Figures 1A, 1B). We also used The Cancer Genome Atlas (TCGA) database to analyze the differential expression of miR-182-5p between adjacent normal tissues and tumor tissues in BC (Figure 1C). TCGA database showed that the area under the curve (AUC) value was close to 0.915 , suggesting that miR-182-5p has a potential diagnostic value for $\mathrm{BC}$ (Figure 1D). The data showed that the difference in miR-182-5p expression was nonsignificant in patients grouped by age and sex but was significant in patients grouped by pathological stage, grade, and lymphatic metastasis status. Thus, these findings suggested that miR-182-5p may be a potential molecular target of BC (Table 1).

miR-182-5p increases BC cell proliferation and migration in vitro. To investigate the effects of miR-182-5p in BC cells, 5637 and T24 cells were transfected with a miR-182-5p mimics or inhibitor, and the expression of miR-182-5p was detected by qRT-PCR. The expression level of miR-182-5p was significantly higher in miR-182-5p mimic-transfected cells than in NC mimic-transfected cells
Table 1. Clinicopathological features of $36 \mathrm{BC}$ patients and the expression of miR-182-5p.

\begin{tabular}{|c|c|c|c|c|c|c|}
\hline \multirow{2}{*}{ Parameter } & \multirow{2}{*}{ Cases } & \multicolumn{4}{|c|}{ miR-182-5p expression } & \multirow[t]{2}{*}{ p-value } \\
\hline & & Low & $\%$ & High & $\%$ & \\
\hline \multicolumn{7}{|l|}{ Sex } \\
\hline Male & 22 & 5 & 23 & 17 & 77 & 0.927 \\
\hline Female & 14 & 3 & 21 & 11 & 79 & \\
\hline \multicolumn{7}{|c|}{ Age at surgery } \\
\hline$<60$ & 17 & 3 & 18 & 14 & 82 & 0.423 \\
\hline$\geq 60$ & 19 & 5 & 26 & 14 & 74 & \\
\hline \multicolumn{7}{|c|}{ Pathological } \\
\hline pTa-T1 & 12 & 7 & 58 & 5 & 42 & 0.000 \\
\hline pT2-T4 & 24 & 1 & 4 & 23 & 96 & \\
\hline \multicolumn{7}{|l|}{ Grade } \\
\hline Low & 10 & 5 & 50 & 5 & 50 & 0.013 \\
\hline High & 26 & 3 & 12 & 23 & 88 & \\
\hline \multicolumn{7}{|c|}{ Lymph node metastasis } \\
\hline Absent & 10 & 6 & 60 & 4 & 40 & 0.001 \\
\hline Present & 26 & 2 & 8 & 24 & 92 & \\
\hline Total & 36 & 8 & & 28 & & \\
\hline
\end{tabular}

A

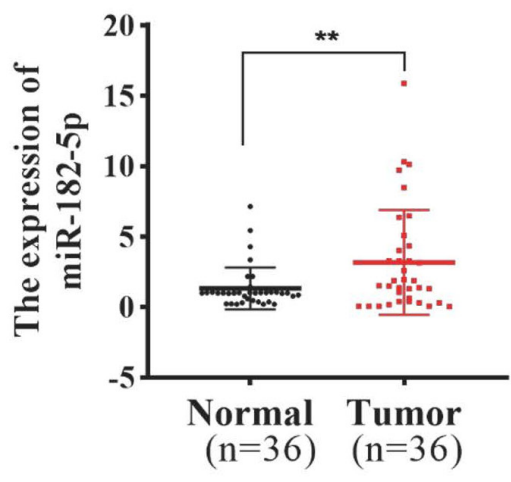

C

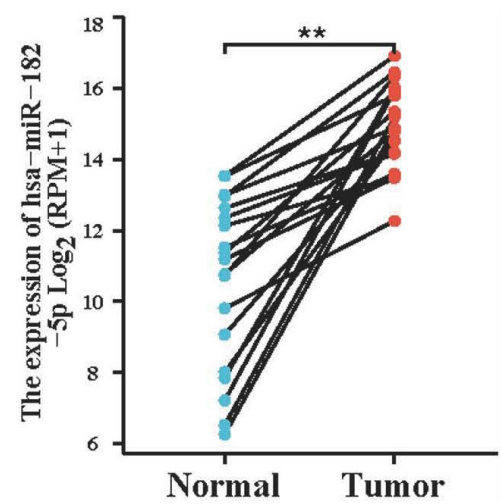

B
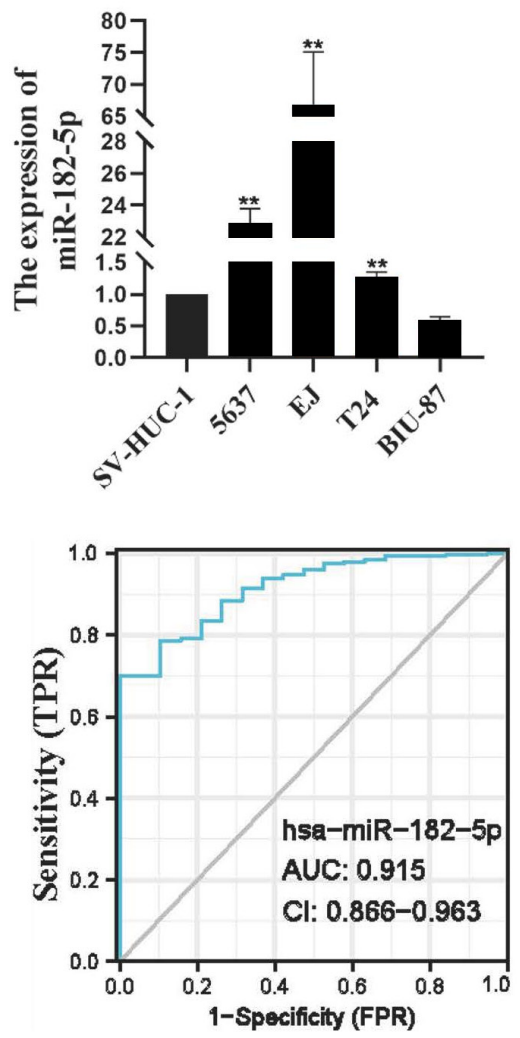

Figure 1. miR-182-5p is highly expressed in BC tissues and cells. A, B) Quantitative real-time PCR (qRT-PCR) revealed that miR-182-5p was upregulated in BC tissues $(n=36)$ and cell lines (5637, EJ, T24, and BIU-87). The error bars represent the SEM $(n=3) .{ }^{* *} p<0.01$ (Student's t-test). C) TCGA data expression analysis of miR-182-5p in 19 BC tissues and adjacent nonmalignant BC tissues. D) Receiver operating characteristic (ROC) curves for miR-182-5p in TCGA dataset. 
$(\mathrm{p}<0.05$, Figure $2 \mathrm{~A})$. The wound-healing assay showed that miR-182-5p overexpression promoted migration (Figure 2B) and that the downregulation of miR-182-5p inhibited the migration of BC cells (Supplementary Figure S1A). These results were further confirmed through Transwell assays (Figure 2C, Supplementary Figure 1B). EdU and colony formation experiments showed that upregulation of miR-182-5p promoted the proliferation of BC cells (Figures 2D, 2E), while downregulation of miR-182-5p had the opposite effect (Supplementary Figures 1C, 1D). In summary, our results indicated that miR-182-5p promotes the migration and proliferation of $\mathrm{BC}$ cells.

FOXF2 is the direct downstream target gene of miR-182-5p in BC. To obtain more accurate prediction results, we selected target genes with high prediction scores in the database. The intersection of the TarBase, ENCORI, and miRDB predictions revealed a single potential mRNA candidate, namely, FOXF2 (Figure 3A). To confirm the miRNAtarget relationship between miR-182-5p and FOXF2, T24 and 5637 cells were transfected with a miR-182-5p mimic, inhibitor, or control. We found that FOXF2 mRNA levels were downregulated in the mimic group and upregulated in the inhibitor group (Figures 3B, 3C). Luciferase reporter gene analysis showed that miR-182-5p significantly reduced the luciferase activity of the FoxF2 luciferase plasmid in the WT group compared to that in the MUT group (Figures 3D, 3E). These data demonstrated that FOXF2 is a direct downstream target of miR-182-5p.

FOXF2 is a tumor suppressor gene with low expression in BC tissues and cells. We used qRT-PCR to detect FOXF2 expression in $\mathrm{BC}$ cell lines and 36 pairs of $\mathrm{BC}$ tissues to determine its expression patterns. The results showed that FOXF2 expression was significantly reduced in $\mathrm{BC}$ cell lines and tissues (Figures 4A, 4B), suggesting that FOXF2 may act as a tumor suppressor gene in BC. Similarly, we further explored the change in FOXF2 at the protein level through IHC, and the results showed that FOXF2 was expressed at low levels in BC tissues (Figure 4C).
A

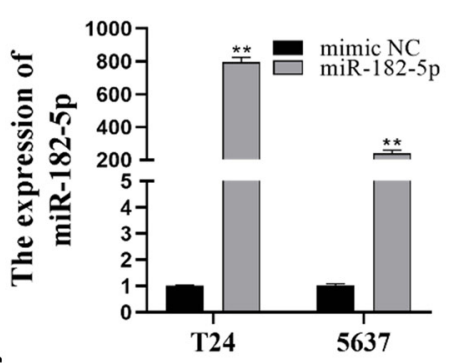

C

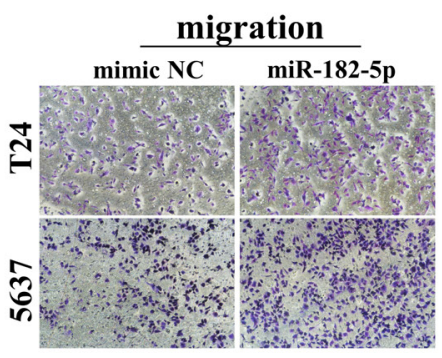

B

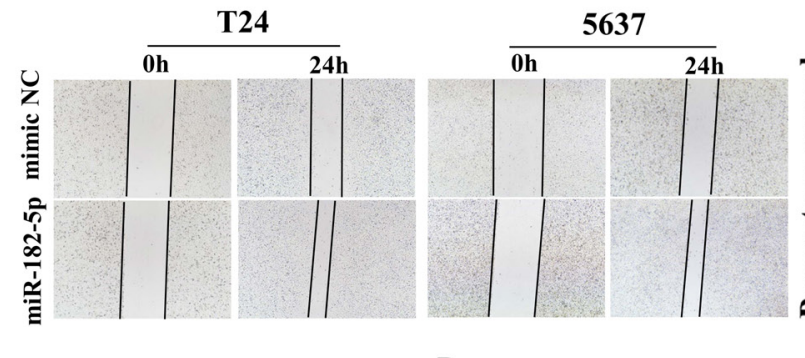

D
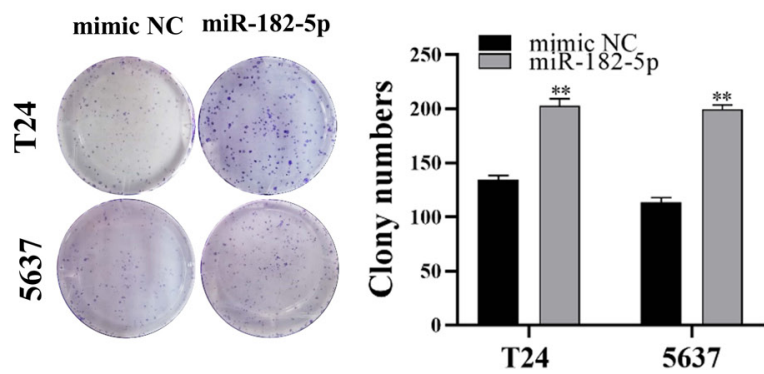

$\mathbf{E}$

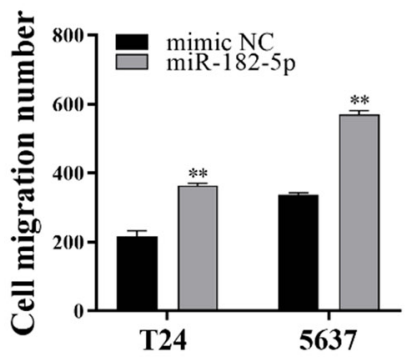

5637
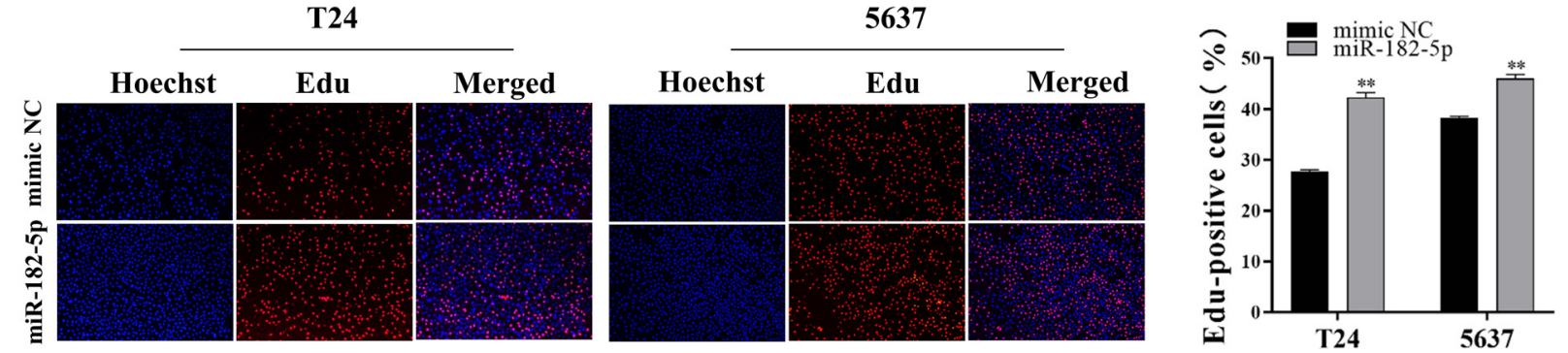

Figure 2. miR-182-5p increases BC cell migration and proliferation in vitro. A) qRT-PCR detection showed that miR-182-5p was significantly increased in the overexpression group. B, C) Wound-healing and Transwell assays showed that miR-182-5p promoted the migration of T24 and 5637 cells. D, E) miR-182-5p enhanced the proliferation of T24 and 5637 cells. ${ }^{* *} \mathrm{p}<0.01$ 
A

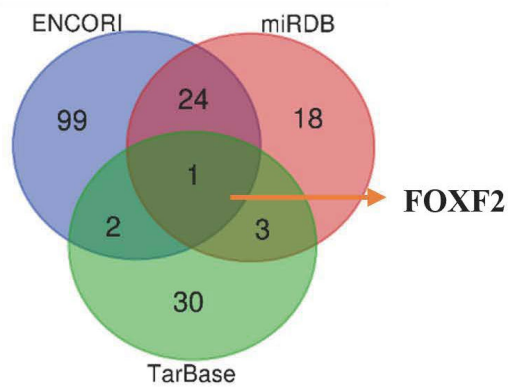

D

B

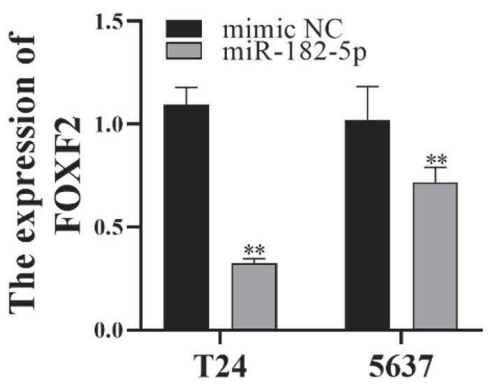

E

c
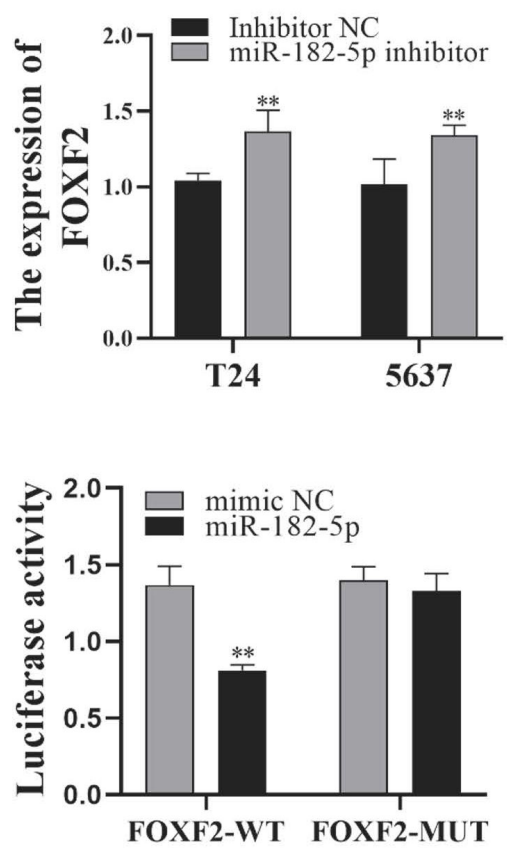

Figure 3. FOXF2 is the direct downstream target gene of miR-182-5p in BC. A) Schematic illustration showing overlapping of the target mRNA of miR-182-5p predicted by TarBase, ENCORI, and miRDB. B, C) miR-182-5p regulated the expression of FOXF2. D, E) Luciferase reporter assay in T24 cells cotransfected with miR-182-5p or NC mimics as well as psiCHECK-2-wild type FOXF2 (FOXF2-wt) or psiCHECk-2-mutant type FOXF2 (FOXF2mut) plasmids. ${ }^{* *} \mathrm{p}<0.01$

We next used a FOXF2 overexpression plasmid and FOXF2 siRNA to further verify this hypothesis at the mRNA and protein levels (Figure 4D, Supplementary Figures S2A-S2D). FOXF2 inhibited BC cell migration in the wound-healing assay, and FOXF2 downregulation accelerated BC cell migration, which was further confirmed by the Transwell assay (Figures 4E, 4F, Supplementary Figures 3A, 3B). Colony formation and EdU experiments showed that overexpression of FOXF2 inhibited the proliferation of BC while silencing FOXF2 expression accelerated the proliferation of BC cells (Figures 4G, 4H, Supplementary Figures S3C, S3D). The above experimental studies suggested that FOXF2 is a tumor suppressor gene in $\mathrm{BC}$.

miR-182-5p and FOXF2 mediate proliferation and migration via the $\mathrm{SHH}$ signaling pathway. The $\mathrm{SHH}$ pathway has been reported to promote tumor progression. Western blotting analysis demonstrated that the SHH pathway was highly expressed in T24 and 5637 cells compared to SV-HUC-1 cells (Supplementary Figure S4A). Western blotting assays also demonstrated that the miR-182-5p mimics reduced the expression of FOXF2 but increased the expression of SHH, SMO, and Gli1. Accordingly, the miR-182-5p inhibitor increased FOXF2 expression but decreased the $\mathrm{SHH}, \mathrm{SMO}$, and Gli1 expression levels in BC cells (Figures 5A, 5B). We also transfected the FOXF2 overexpression plasmid and FOXF2 siRNA into 5637 and T24 cells. FOXF2 overexpression significantly increased FOXF2 protein expression and inhibited the $\mathrm{SHH}$ pathway. In contrast, silencing FOXF2 significantly decreased FOXF2 expression and activated the $\mathrm{SHH}$ pathway (Figures 5C, 5D).

To further explore the mechanism, we designed a series of rescue experiments. The results showed that FOXF2 overexpression significantly restored the miR-182-5p-induced reduction in migration (Figures $5 \mathrm{E}-5 \mathrm{G}$ ) and proliferation (Figures 5H, 5I) of BC cells. Moreover, western blotting analysis demonstrated that FOXF2 attenuated the activation of the SHH pathway induced by the miR-182-5p mimics at the protein level (Figures 5J, 5K).

miR-182-5p increases BC cell proliferation and migration in vivo. To evaluate whether miR-182-5p impacts tumorigenicity in vivo, we used T24 cells for subsequent in vivo mouse experiments. After euthanizing the mice after 4 weeks of growth, we found that the volume and weight of the tumors were higher in the miR-182-5p mimic group compared to the NC mimic group (Figures 6A, 6B). Compared to the NC mimic group, the expression of FOXF2 was significantly decreased in the miR-182-5p mimic group, and the expression of $\mathrm{SHH}$ pathway components was increased (Figure 6C). These results suggested that miR-182-5p may enhance the proliferation and migration of BC cells. 
A

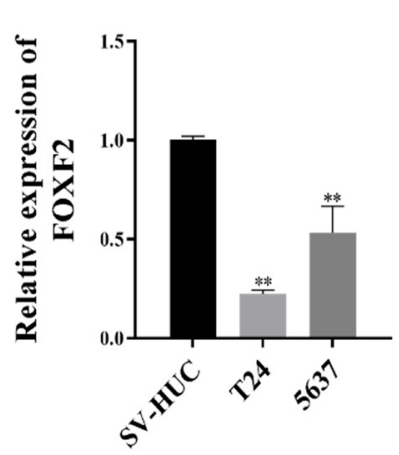

D

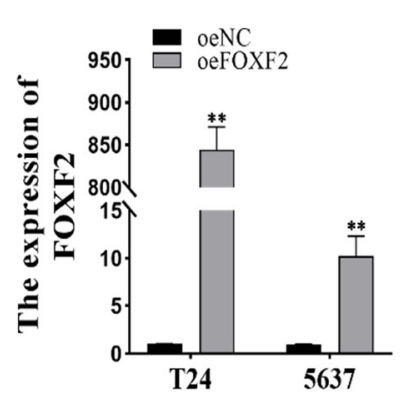

F

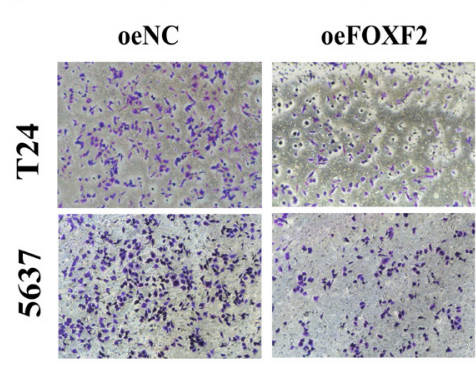

H

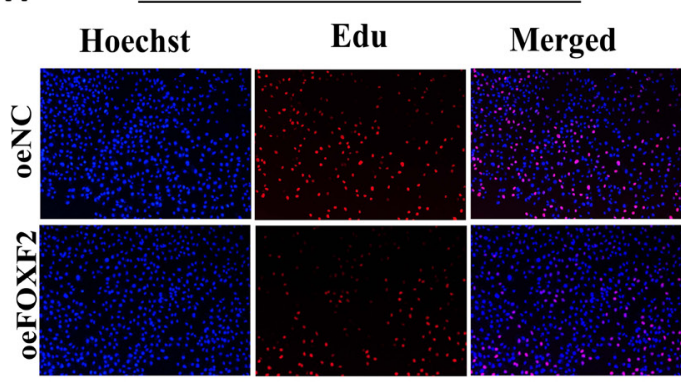

C
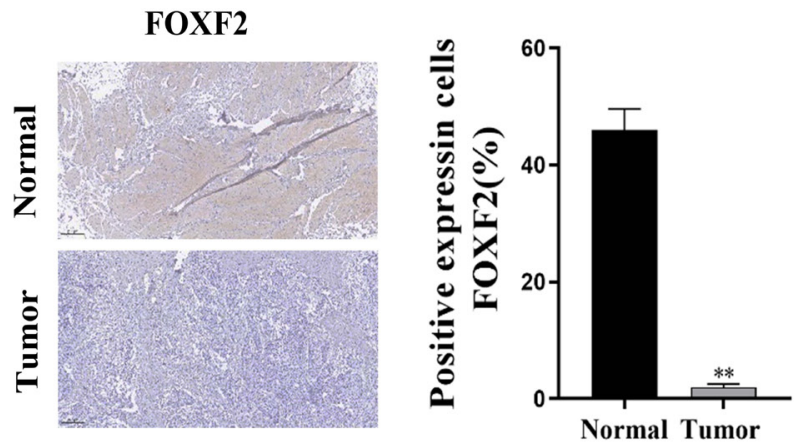

T24

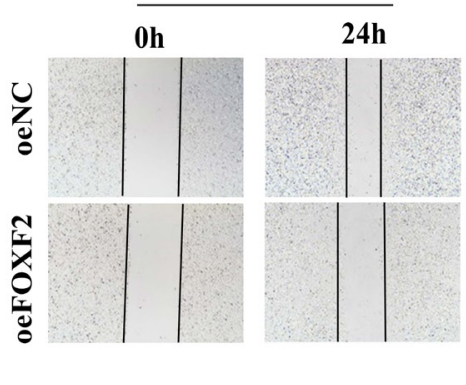

E

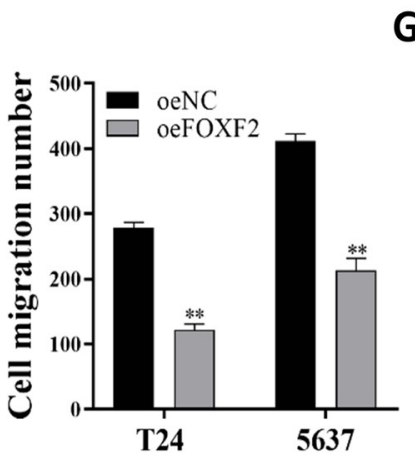

G
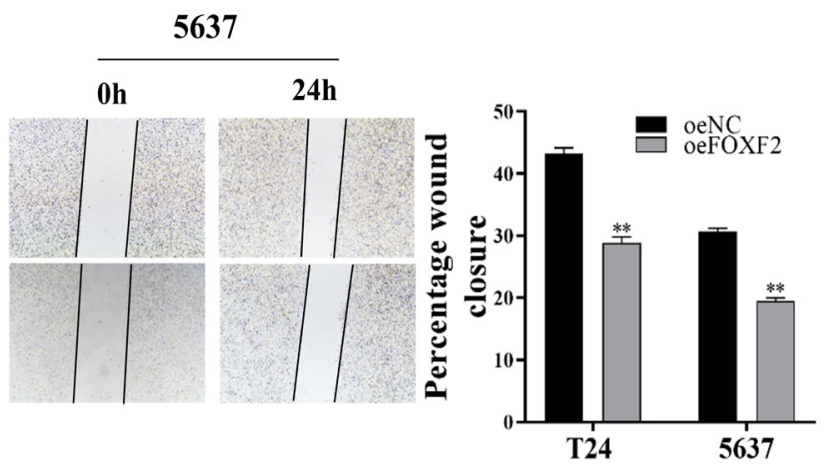

G

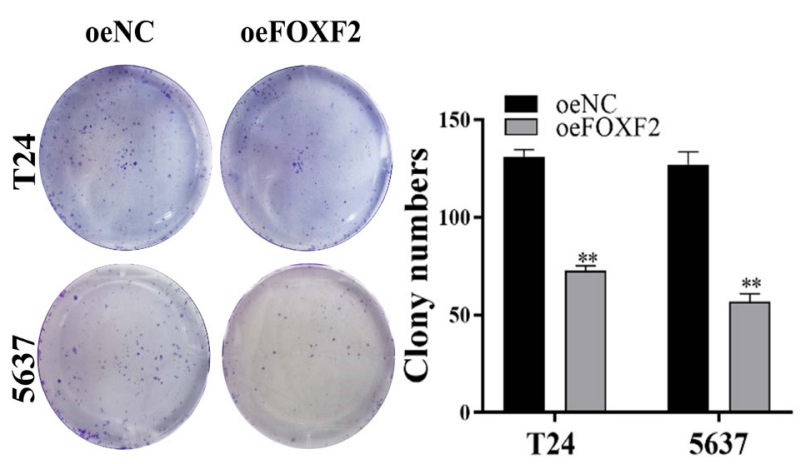

5637
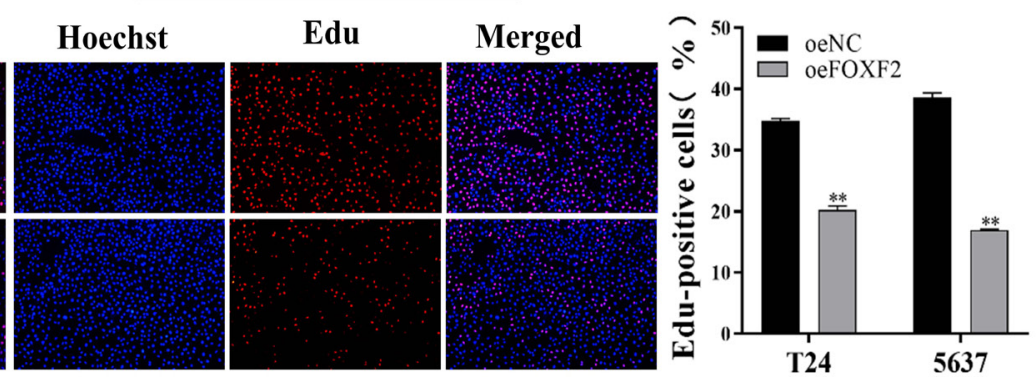

Figure 4. FOXF2 is a tumor suppressor gene with low expression in BC tissues and cells. A) FOXF2 was expressed at low levels in T24 and 5637 cells. B) qRT-PCR data revealed that FOXF2 was downregulated in BC tissues. C, D) Immunohistochemical staining revealed that FOXF2 was expressed at low levels in BC tissues. E) The overexpression of FOXF2 in T24 and 5637 cells was verified by qRT-PCR. F) Wound-healing assay showed that FOXF2 overexpression inhibited the migration of T24 and 5637 cells. G) Transwell assays demonstrated that overexpression of FOXF2 inhibited the migration of T24 and 5637 cells. H) Overexpression of FOXF2 in T24 and 5637 cells inhibited their colony formation ability. EdU assay showed that FOXF2 inhibited the proliferation of T24/5637 cells. ${ }^{* *} \mathrm{p}<0.01$ 
A

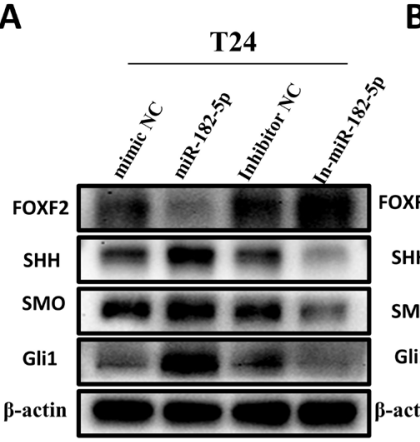

E
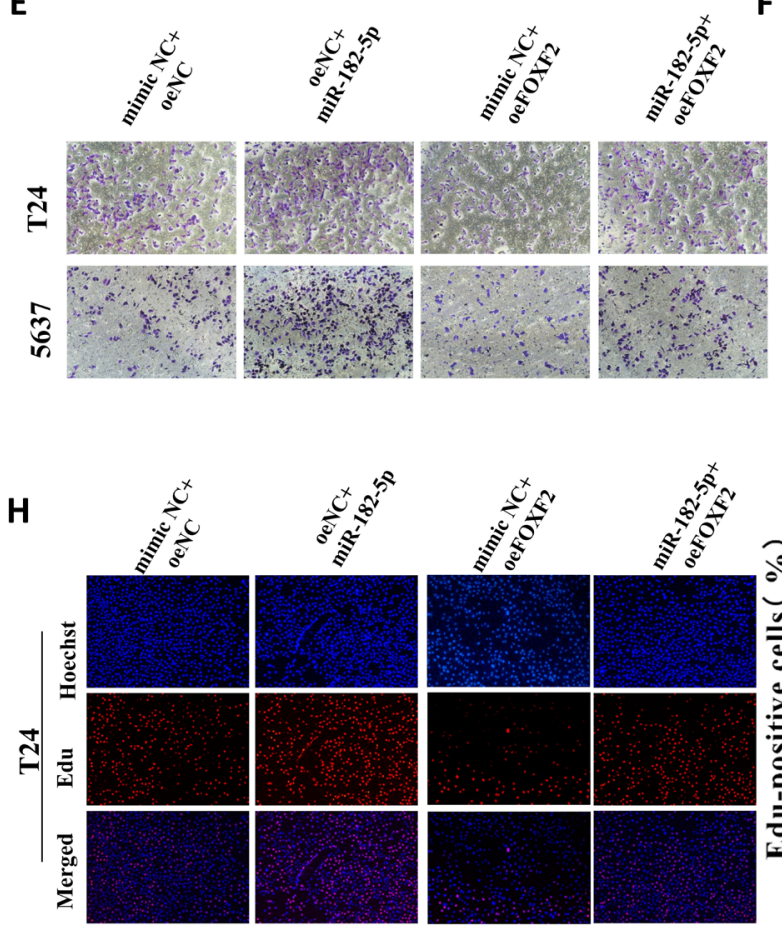

I

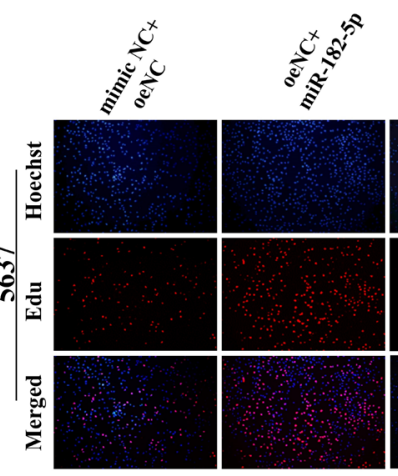

B

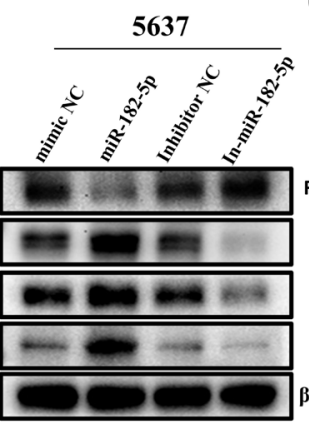

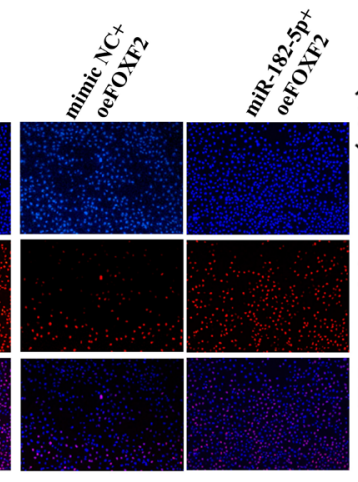

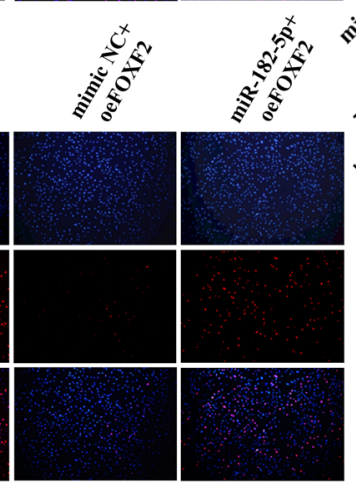

C

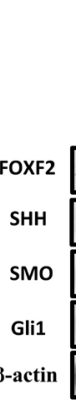

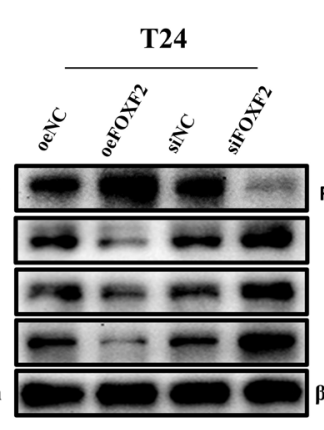

D

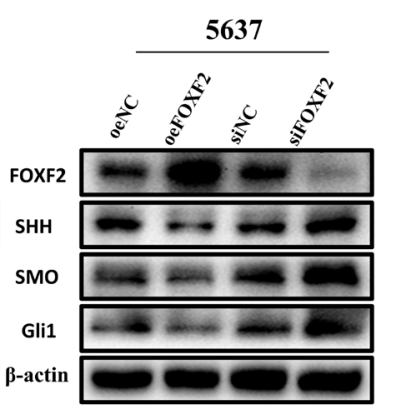

G

$$
\text { 焉 }
$$
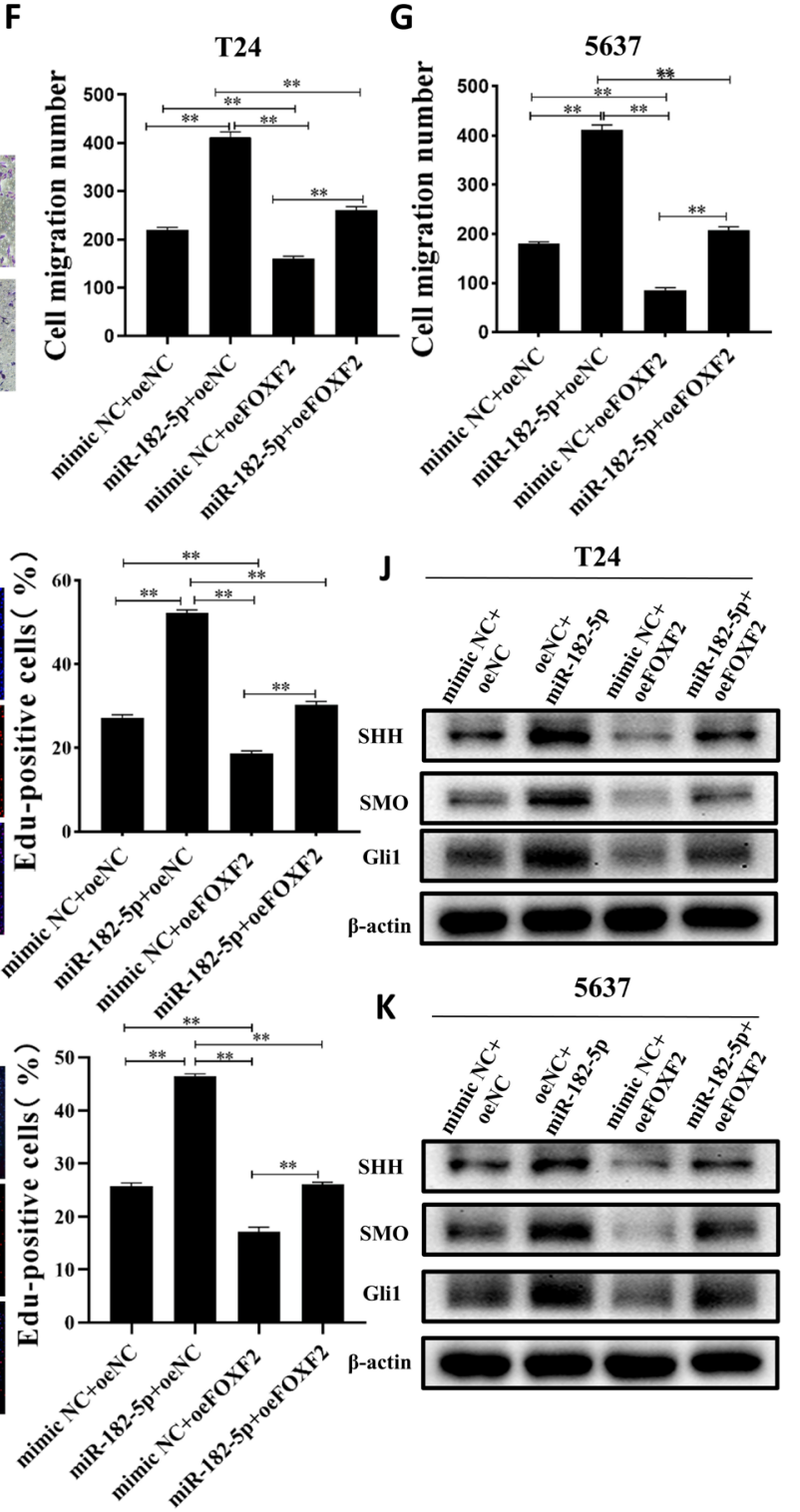

Figure 5. miR-182-5P/FOXF2 affects proliferation and migration through the regulation of the SHH signaling pathway. A, B) miR-182-5p regulates FOXF2. miR-182-5p upregulated the expression of SHH, SMO, and Gli1 in T24 and 5637 cells, while In-miR-182-5p downregulated the expression of SHH, SMO, and Gli1. C, D) FOXF2 overexpression downregulated the expression of SHH, SMO, and Gli1 in T24 and 5637 cells, while siFOXF2 upregulated the expression of SHH, SMO, and Gli1. E-G) FOXF2 counteracted the enhanced effect of the miR-182-5p mimics on cell migration. H, I) FOXF2 counteracted the enhanced effect of the miR-182-5p mimics on cell proliferation. J, K) Western blot indicating that FOXF2 counteracted the upregulation effect of miR-182-5p on SHH, SMO, and Gli1. ${ }^{* *}$ p $<0.01$ 


\section{Discussion}

Recent findings have suggested that miRNAs play an important role in BC and other malignancies. Many studies have confirmed the miRNA pathways of action of BC [20]. It is well known that through the complete or incomplete pairing of miRNAs with the 3'UTR of mRNAs, miRNAs block translation or promote the degradation of target mRNAs, thereby reducing the expression of the corresponding proteins to achieve their biological functions. The dysregulation of miRNAs and their target genes is an important factor affecting the development of tumors [10]. However, the exact role of miRNA dysregulation in the pathogenesis of BC is still unclear and needs to be further explored. In our study, the expression level of miR-182-5p was significantly increased in BC tissues and cells compared to adjacent normal tissues and SU-HUC-1 cell lines, respectively. Furthermore, the mechanism by which miR-182-5p promotes BC development was further studied.

In the present study, bioinformatics algorithms (TarBase [21], ENCORI [22], and miRDB [23]) determined that FOXF2 is a candidate target for miR-182-5p. Forkhead box transcription factor F2 (FOXF2) belongs to the FOX family and is a key transcription factor that regulates the differentiation of tissue cell mesenchyme. FOXF2 regulates gene expression by regulating the transcriptional activity of genes, thereby regulating cellular biological processes [24]. FOXF2 affects epithelial-mesenchymal transition, but the exact mechanism is not clear [25]. The role and mechanism of the FOXF2 gene in BC have not been previously reported. In the present study, through gain- or loss- of-function analyses, we found that FOXF2 inhibited the migration and proliferation of BC cells. To further investigate the mechanism of FOXF2 in $\mathrm{BC}$, we investigated FOXF2 together with EMT-related pathways, and we found that FOXF2 was involved in the regulation of the $\mathrm{SHH}$ pathway.

The $\mathrm{SHH}$ pathway plays a protumor role in a variety of cancers [26], including non-small cell lung cancer [27] and liver cancer [28], but the mechanism of the $\mathrm{SHH}$ pathway in $\mathrm{BC}$ has not been elucidated. In BC tissues and cells, SHH is abnormally expressed and associated with progression and pathogenesis [29]. SHH belongs to the hedgehog protein family [30]. Hedgehog proteins activate SMO and promote nuclear translocation of the Gli1 transcription factor, thus
A

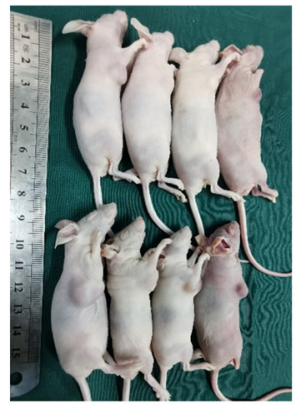

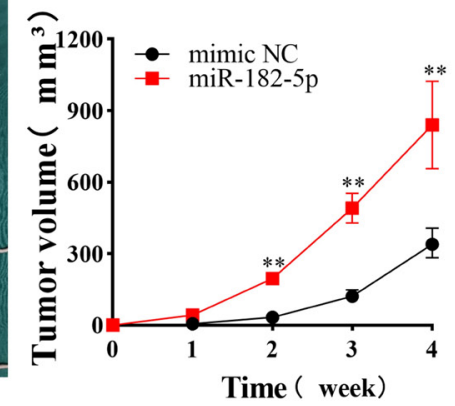

C
B
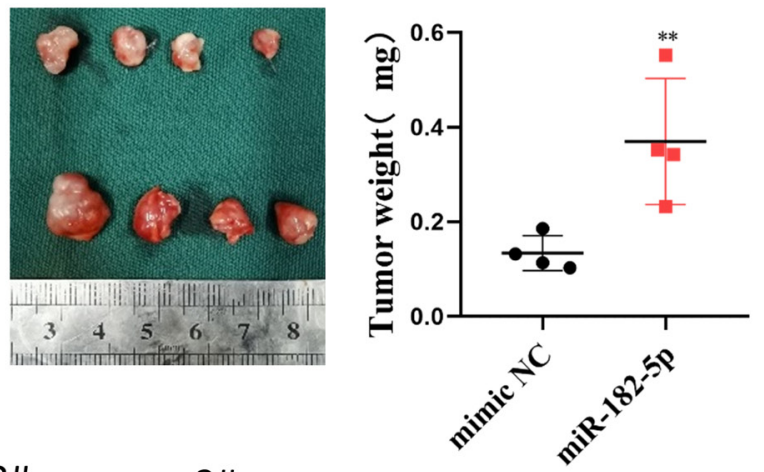

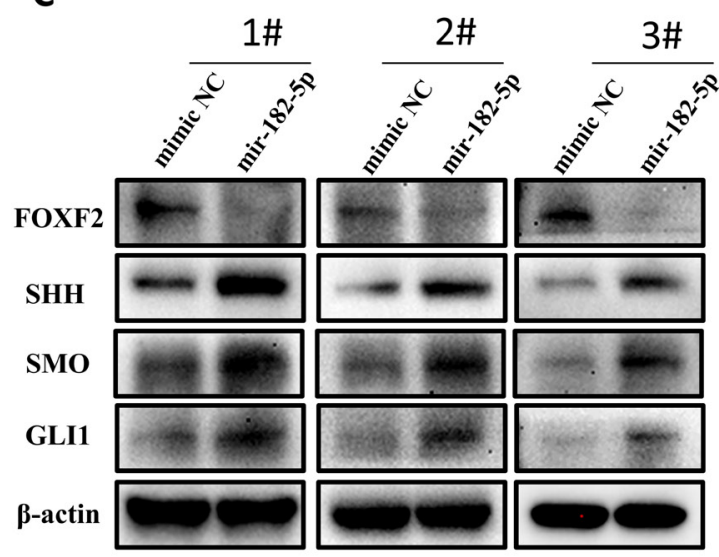

Figure 6. miR-182-5p increases BC proliferation and migration in vivo. A, B) T24 cells transfected with NC and miR-182-5p mimics were subcutaneously injected into nude mice to observe the effect of miR-182-5p on tumor growth. Compared to the NC group, the tumor growth rate and weight significantly increased in miR-182-5p mimic-treated nude mice compared to the NC mimic-treated nude mice. C) FOXF2 in the miR-182-5p overexpression group was decreased, and the $\mathrm{SHH}$ pathway was activated. ${ }^{* *} \mathrm{p}<0.01$ 
affecting downstream target gene expression [31]. In the present study, we found that the SHH signaling pathway was involved in the development and progression of BC. Through gain- or loss-of-function analyses, we demonstrated that miR-182-5p/FOXF2 regulated BC through the SHH pathway. However, the exact mechanism of the effect of FOXF2 on the SHH pathway is still unknown and will be further explored in our future studies.

In conclusion, we found that miR-182-5p effectively inhibits the expression of FOXF2 in BC tissues and cells. We also demonstrated that miR-182-5p promotes the proliferation and invasion of $\mathrm{BC}$ cells by targeting the FOXF2/SHH axis. Our findings suggested that miR-182-5p/FOXF2 may serve as new targets for the treatment of $\mathrm{BC}$, and our results may have potential clinical implications.

Supplementary information is available in the online version of the paper.

Acknowledgments: This research was supported by the National Natural Science Foundation of China (81802559), Anhui Provincial Natural Science Foundation (1908085MH285), Anhui University Provincial Natural Science Research Foundation (KY2018A0260), Funding of "Climbing Peak" Training Program for Innovative Technology team of Yijishan Hospital, Wannan Medical College (KDF2019015), and Funding of "Peak" Training Program for Scientific Research of Yijishan Hospital, Wannan Medical College (KGF2019J09).

\section{References}

[1] SIEGEL RL, MILLER KD, JEMAL A. Cancer statistics, 2018. CA Cancer J Clin 2018; 68: 7-30. https://doi.org/10.3322/ caac. 21442

[2] WU XR. Urothelial tumorigenesis: a tale of divergent pathways. Nat Rev Cancer 2005; 5: 713-725. https://doi. org/10.1038/nrc1697

[3] LIEDBERG F, HAGBERG O, HOLMANG S, HOSSEINI ALIABAD A, JANCKE G et al. Local recurrence and progression of non-muscle-invasive bladder cancer in Sweden: a population-based follow-up study. Scand J Urol 2015; 49: 290-295. https://doi.org/10.3109/21681805.2014.1000963

[4] COLOMBO R. Editorial comment on: Defining early morbidity of radical cystectomy for patients with bladder cancer using a standardized reporting methodology. Eur Urol 2009; 55: 175-176. https://doi.org/10.1016/j.eururo.2008.07.033

[5] MEYER JP, BLICK C, ARUMAINAYAGAM N, HURLEY $\mathrm{K}$, GILLATT D et al. A three-centre experience of orthotopic neobladder reconstruction after radical cystectomy: revisiting the initial experience, and results in 104 patients. BJU Int 2009; 103: 680-683. https://doi.org/10.1111/j.1464410X.2008.08204.X

[6] TRAN L, XIAO JF, AGARWAL N, DUEX JE, THEODORESCU D. Advances in bladder cancer biology and therapy. Nat Rev Cancer 2021; 21: 104-121. https://doi.org/10.1038/ s41568-020-00313-1
[7] WITJES J A, BRUINS HM, CATHOMAS R, COMPERAT EM, COWAN NC et al. European Association of Urology Guidelines on Muscle-invasive and Metastatic Bladder Cancer: Summary of the 2020 Guidelines. Eur Urol 2021; 79: 82-104. https://doi.org/10.1016/j.eururo.2020.03.055

[8] KITA Y, HAMADA A, SAITO R, TERAMOTO Y, TANAKA $\mathrm{R}$ et al. Systematic chemical screening identifies disulfiram as a repurposed drug that enhances sensitivity to cisplatin in bladder cancer: a summary of preclinical studies. Br J Cancer 2019; 121: 1027-1038. https://doi.org/10.1038/s41416-0190609-0

[9] JIA Y, DING X, ZHOU L, ZHANG L, YANG X. Mesenchymal stem cells-derived exosomal microRNA-139-5p restrains tumorigenesis in bladder cancer by targeting PRC1. Oncogene 2021; 40: 246-261. https://doi.org/10.1038/ s41388-020-01486-7

[10] REDDY KB. MicroRNA (miRNA) in cancer. Cancer Cell Int 2015; 15: 38. https://doi.org/10.1186/s12935-015-0185-1

[11] DONG W, BI J, LIU H, YAN D, HE Q et al. Circular RNA ACVR2A suppresses bladder cancer cells proliferation and metastasis through miR-626/EYA4 axis. Mol Cancer 2019; 18: 95. https://doi.org/10.1186/s12943-019-1025-Z

[12] LI Y, ZHENG F, XIAO X, XIE F, TAO D et al. CircHIPK3 sponges miR-558 to suppress heparanase expression in bladder cancer cells. EMBO Rep 2017; 18: 1646-1659. https:// doi.org/10.15252/embr.201643581

[13] YAN S, WANG H, CHEN X, LIANG C, SHANG W et al. MiR-182-5p inhibits colon cancer tumorigenesis, angiogenesis, and lymphangiogenesis by directly downregulating VEGF-C. Cancer Lett 2020; 488: 18-26. https://doi. org/10.1016/j.canlet.2020.04.021

[14] SEIDL C, PANZITT K, BERTSCH A, BRCIC L, SCHEIN S et al. MicroRNA-182-5p regulates hedgehog signaling pathway and chemosensitivity of cisplatin-resistant lung adenocarcinoma cells via targeting GLI2. Cancer Lett 2020; 469: 266-276. https://doi.org/10.1016/j.canlet.2019.10.044

[15] SANG Y, CHEN B, SONG X, LI Y, LIANG Y et al. circRNA_0025202 Regulates Tamoxifen Sensitivity and Tumor Progression via Regulating the miR-182-5p/FOXO3a Axis in Breast Cancer. Mol Ther 2019; 27: 1638-1652. https://doi. org/10.1016/j.ymthe.2019.05.011

[16] CAO MQ, YOU AB, ZHU XD, ZHANG W, ZHANG YY et al. miR-182-5p promotes hepatocellular carcinoma progression by repressing FOXO3a. J Hematol Oncol 2018; 11: 12. https://doi.org/10.1186/s13045-018-0555-y

[17] LU JT, TAN CC, WU XR, HE R, ZHANG X et al. FOXF2 deficiency accelerates the visceral metastasis of basal-like breast cancer by unrestrictedly increasing TGF-beta and miR-182-5p. Cell Death Differ 2020; 27: 2973-2987. https:// doi.org/10.1038/s41418-020-0555-7

[18] HIGASHIMORI A, DONG Y, ZHANG Y, KANG W, NAKATSU G et al. Forkhead Box F2 Suppresses Gastric Cancer through a Novel FOXF2-IRF2BPL-beta-Catenin Signaling Axis. Cancer Res 2018; 78: 1643-1656. https://doi. org/10.1158/0008-5472.CAN-17-2403

[19] WANG A, JIN C, LI H, QIN Q, LI L. LncRNA ADAMTS9-AS2 regulates ovarian cancer progression by targeting miR-1825p/FOXF2 signaling pathway. Int J Biol Macromol 2018; 120: 1705-1713. https://doi.org/10.1016/j.ijbiomac.2018.09.179 
[20] LI Y, LI G, GUO X, YAO H, WANG G et al. Non-coding RNA in bladder cancer. Cancer Lett 2020; 485: 38-44. https://doi. org/10.1016/j.canlet.2020.04.023

[21] SETHUPATHY P, CORDA B, HATZIGEORGIOU G. TarBase: A comprehensive database of experimentally supported animal microRNA targets. RNA 2006; 12: 192-197. https://doi.org/10.1261/rna.2239606

[22] LI JH, LIU S, ZHOU H, QU LH, YANG JH. starBase v2.0: decoding miRNA-ceRNA, miRNA-ncRNA and protein-RNA interaction networks from large-scale CLIP-Seq data. Nucleic Acids Res 2014; 42: D92-D97. https://doi.org/10.1093/ nar/gkt1248

[23] CHEN Y, WANG X. miRDB: an online database for prediction of functional microRNA targets. Nucleic Acids Res 2020; 48: D127-D131. https://doi.org/10.1093/nar/gkz757

[24] MEYER-SCHALLER N, HECK C, TIEDE S, YILMAZ M, CHRISTOFORI G. Foxf2 plays a dual role during transforming growth factor beta-induced epithelial to mesenchymal transition by promoting apoptosis yet enabling cell junction dissolution and migration. Breast Cancer Res 2018; 20: 118. https://doi.org/10.1186/s13058-018-1043-6

[25] CHITSAZZADEH V, COARFA C, DRUMMOND JA, NGUYEN T, JOSEPH A et al. Cross-species identification of genomic drivers of squamous cell carcinoma development across preneoplastic intermediates. Nat Commun 2016; 7: 12601. https://doi.org/10.1038/ncomms12601
[26] GIROUX-LEPRIEUR E, COSTANTINI A, DING V, HE B. Hedgehog Signaling in Lung Cancer: From Oncogenesis to Cancer Treatment Resistance. Int J Mol Sci 2018; 19: 2835. https://doi.org/10.3390/ijms19092835

[27] LEI X, ZHONG Y, HUANG L, LI S, FU J et al. Identification of a novel tumor angiogenesis inhibitor targeting Shh/Gli1 signaling pathway in Non-small cell lung cancer. Cell Death Dis 2020; 11: 232. https://doi.org/10.1038/s41419-020-2425-0

[28] ZHANG K, CHE S, PAN C, SU Z, ZHENG S et al. The SHH/ Gli axis regulates CD90-mediated liver cancer stem cell function by activating the IL6/JAK2 pathway. J Cell Mol Med 2018; 22: 3679-3690. https://doi.org/10.1111/jcmm.13651

[29] ISLAM SS, MOKHTARI RB, NOMAN AS, UDDIN M, RAHMAN MZ et al. Sonic hedgehog (Shh) signaling promotes tumorigenicity and stemness via activation of epithelial-to-mesenchymal transition (EMT) in bladder cancer. Mol Carcinog 2016; 55: 537-551. https://doi.org/10.1002/ mc.22300

[30] ZHANG Y, BULKLEY DP, XIN Y, ROBERTS KJ, ASARNOW DE et al. Structural Basis for Cholesterol Transport-like Activity of the Hedgehog Receptor Patched. Cell 2018; 175: 1352-1364 e14. https://doi.org/10.1016/j.cell.2018.10.026

[31] CARBALLO GB, HONORATO JR, DE LOPES GPF, SPOHR T. A highlight on Sonic hedgehog pathway. Cell Commun Signal 2018; 16: 11. https://doi.org/10.1186/s12964-0180220-7 
https://doi.org/10.4149/neo_2021_210903N1266

\section{miRNA-182-5p promotes human bladder cancer proliferation and migration through the FOXF2/SHH axis}

Ze ZHANG ${ }^{1,2, *}$, Chong WANG ${ }^{1,2, *}$, Tiantian LIU $^{1,2}$, Zhao TANG ${ }^{1}$, Rucheng YAN ${ }^{1}$, Chen ZHANG ${ }^{1}$, Chao CHENG ${ }^{1,2}$, Jiawei WANG ${ }^{1,2}$, Hao WANG ${ }^{1,2}$, Houbao HUANG ${ }^{1, *}$, Yawei LI ${ }^{1, *}$

Supplementary Information

A

T24

5637
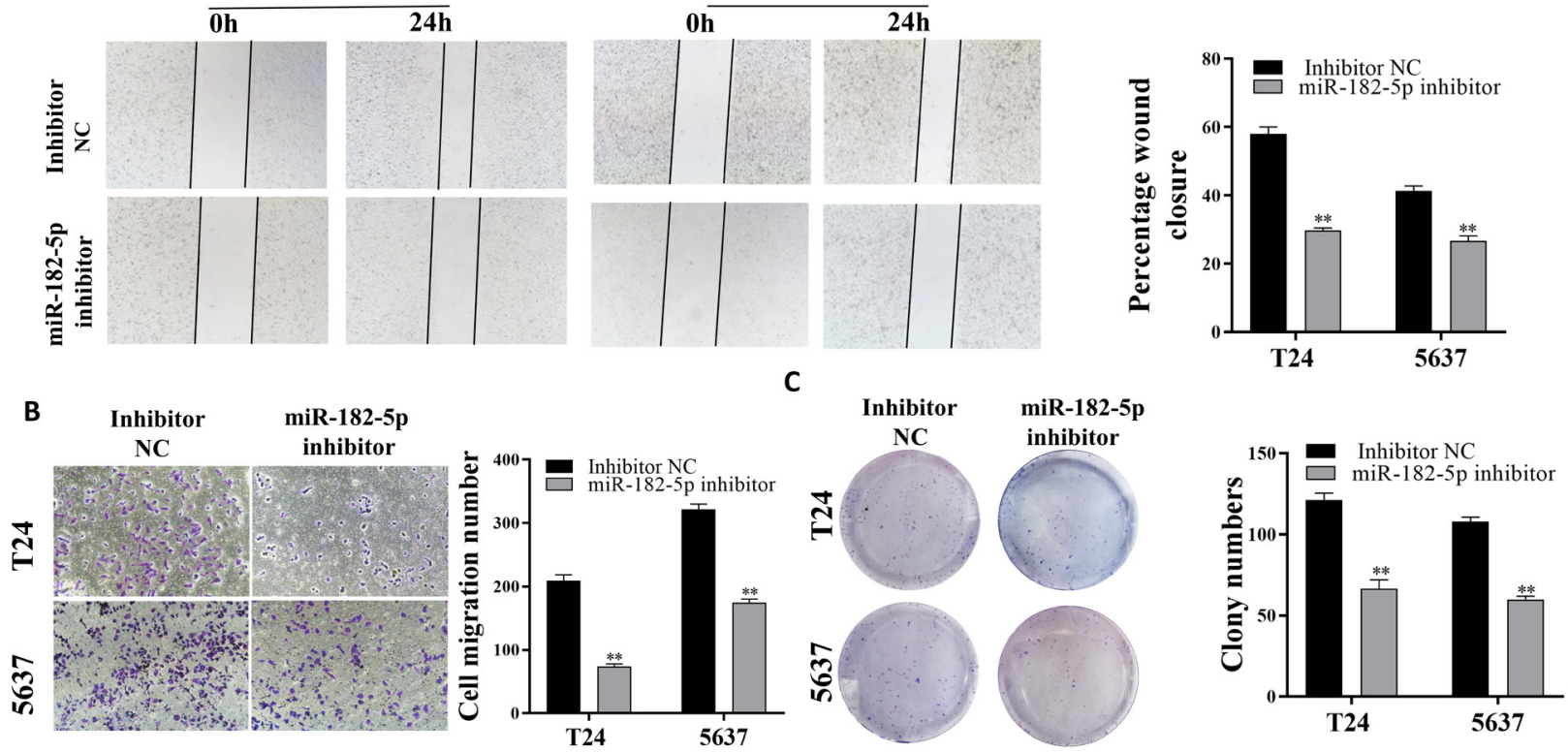

D

T24
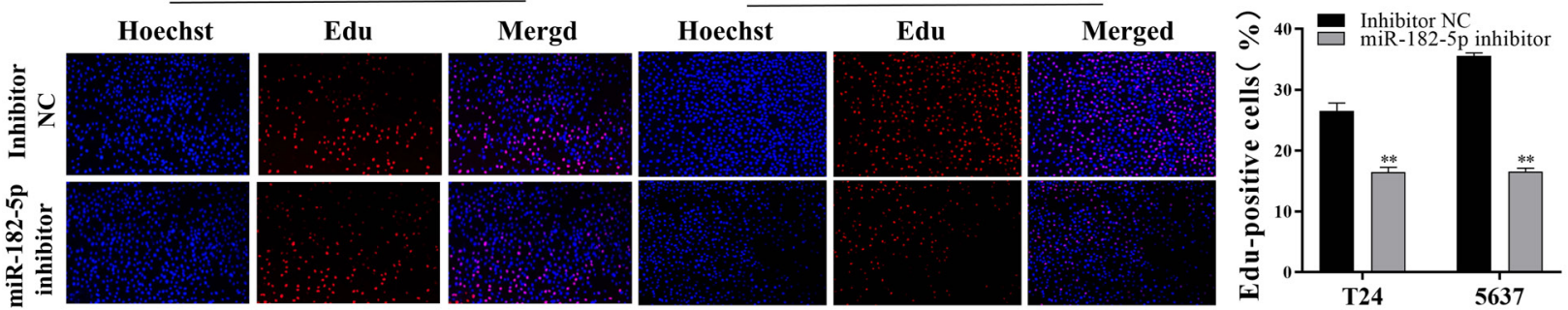

Supplementary Figure S1. Inhibition of the expression of miR-182-5p can inhibit the proliferation and migration of bladder cancer. A, B) Woundhealing and transwell experiments showed that miR-182-5p inhibitor suppress T24 and 5637 cells migration. C, D) Clonal formation assay and EDU demonstrated that inhibition of miR-182-5p could inhibit the proliferation of bladder cancer. ${ }^{* *} \mathrm{p}<0.01$ 


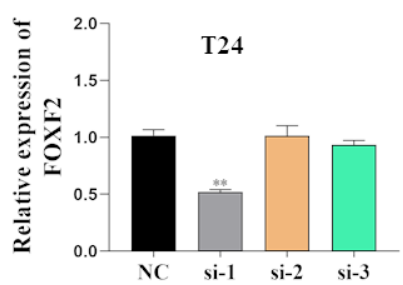

$\mathrm{C}$

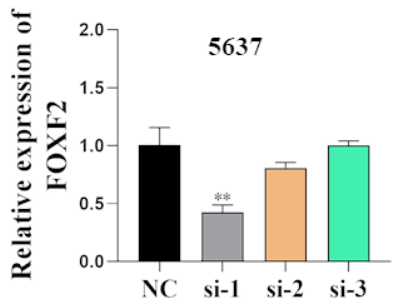

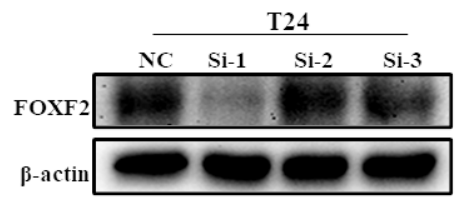

D

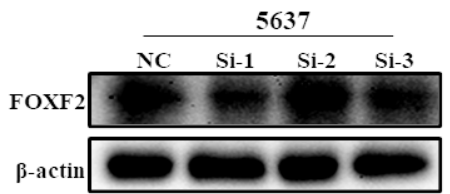

Supplementary Figure S2. siFOXF2 can effectively inhibit the expression of FOXF2. A, C) The interference effect of siFOXF2 was verified in T24 and 5637 cell lines. B, D) Western blotting to verify the interference effect of siFOXF2 in T24 and 5637 cell lines. ${ }^{* *}$ p $<0.01$

A

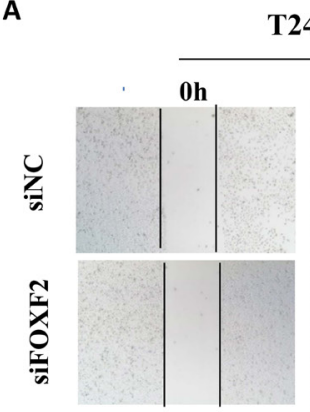

B

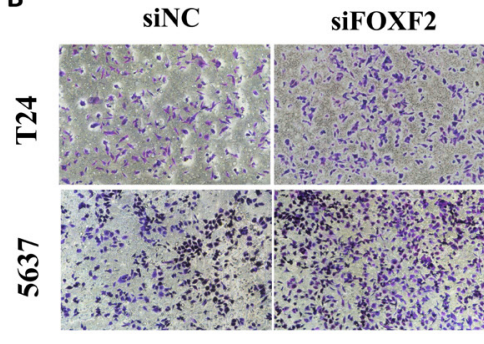

$\mathbf{T 2 4}$

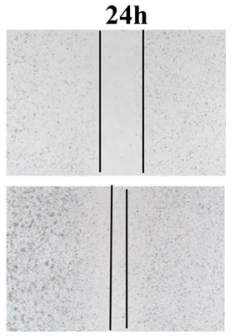

SiFOXF2
5637

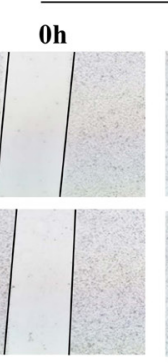

$24 \mathrm{~h}$

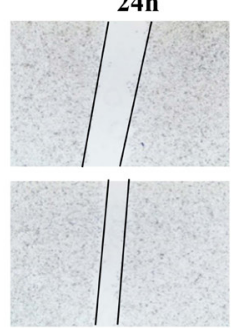

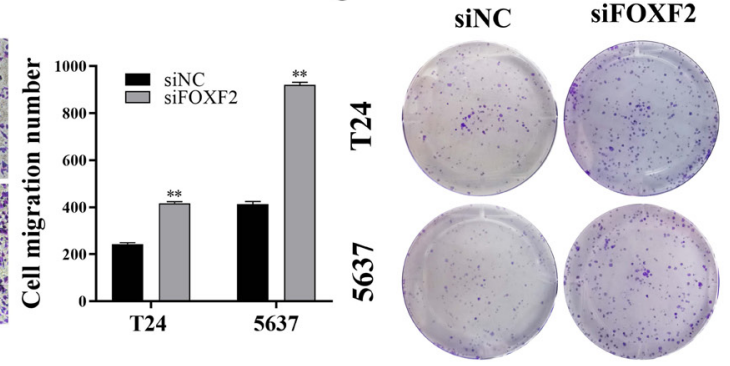

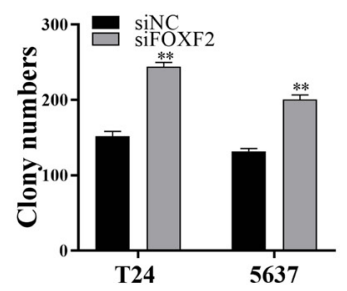

D
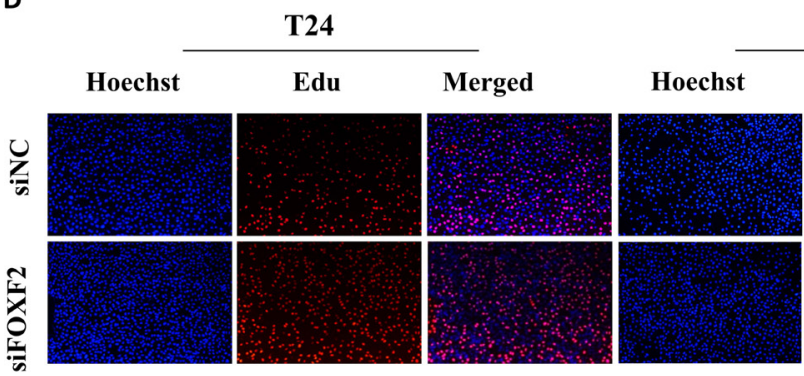

5637
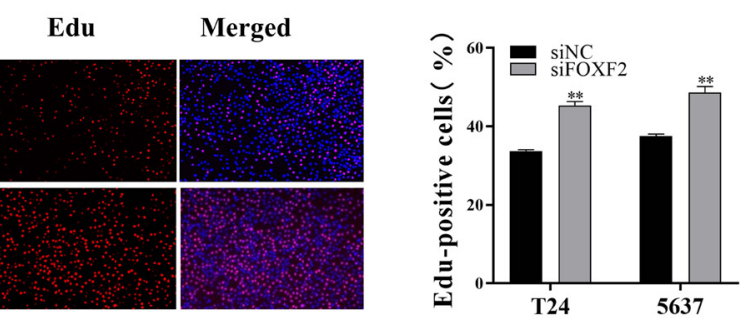

Supplementary Figure S3. Inhibition of FOXF2 expression can promote the proliferation and migration of bladder cancer. A, B) Wound-healing and transwell experiments showed that interfering with FOXF2 expression promote T24/5637 cell migration. C, D) Clonal formation assay and EDU demonstrated that inhibition of FOXF 2 could promote the proliferation of bladder cancer. ${ }^{\star *} \mathrm{p}<0.01$ 


\section{SV-HUC-1 T24 $\quad 5637$}

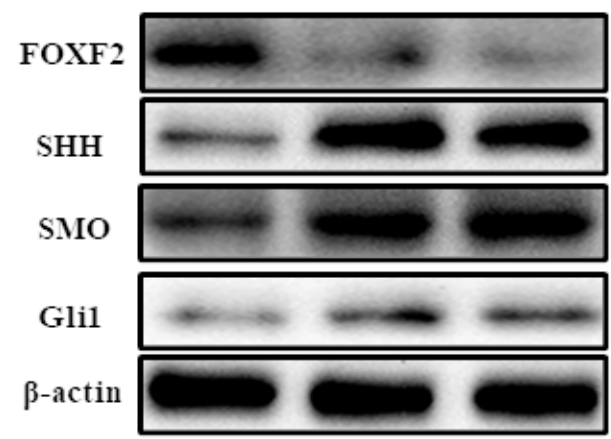

Supplementary Figure S4. The expression of the SHH pathway is elevated in bladder cancer cells. Compared with SV-HUC-1 cells, SHH pathway expression was increased in T24, 5637 cell lines. 